\title{
Neonatal aortic coarctation: a spectrum of anatomic lesions repaired trough left thoracotomy in 22 years experience
}

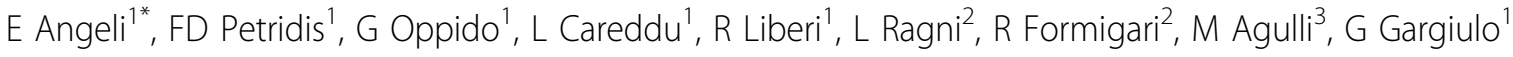 \\ From 23rd World Congress of the World Society of Cardio-Thoracic Surgeons \\ Split, Croatia. 12-15 September 2013
}

\section{Background}

To define the incidence of aortic recoarctation and intracranial aneurysms (IAs) after neonatal aortic coarctation $(\mathrm{CoA})$ repair through left thoracotomy.

\section{Methods}

One hundred and thirty-four patients underwent CoA repair from January 1990 to December 2012 (mean FU $115.6 \pm 82.9$ months). Mean age was $11.5 \pm 7.6$ days (range 0 -30 days). Mean weight was $3.0 \pm 0.7 \mathrm{~kg}, 26.1 \%$ under $2.5 \mathrm{~kg}$ of weight. 88 patients $(65.7 \%)$ presented isolated CoA,36 (26.9\%) associated VSD, 10 (7.5\%) associated complex cardiac defects. All patients were treated through left thoracotomy, $79.9 \%$ with end to end extended anastomosis, 7.4\% with prosthetic and 12.7\% with subclavian patch. Concomitant pulmonary artery banding was performed in 28 patients (21.1\%). During follow up all patients underwent thoracic aortic MR and cardiological evaluation. Cerebral MR angiography was performed to avoid the risk of the association between neonatal CoA repair and IAs development.

\section{Results}

No patients with isolated coarctation died. 3 early deaths $(2.2 \%)$ occurred in patients with complex cardiac defects. Incidence of late mortality was 3.0\%. 3/131 died after complex cardiac defects repair, 1/131 for non cardiac reasons. Freedom from balloon angioplasty was $88.1 \%$ at 10 years, without statistical difference between patients with body weight $<2.5 \mathrm{~kg}$ and surgical techniques. Severe recoarctation was statistical significant in patients with subaortic valve stenosis $(\mathrm{p}<0.021)$. No patients required aortic reinterventions. MR angiography showed no evidence of intracranial aneurysm,or other vascular malformations development.

\section{Conclusion}

In case of neonatal aortic coarctation isolated or associated with cardiac defects requiring concomitant palliative procedures, the left thoracotomy approach appears safe and feasible even in patients with low birth weight without increased risk of aortic recoarctation. The role of potentially associated risk factors for the development of intracranial aneurisms is minimized.

\section{Authors' details}

${ }^{1}$ Pediatric and Adult Congenital Cardiac Surgery Unit, S. Orsola-Malpighi Hospital, University of Bologna Medical School, Bologna, Italy. ${ }^{2}$ Pediatric and Adult Congenital Cardiology Unit, S. Orsola-Malpighi Hospital, University of Bologna Medical School, Bologna, Italy. ${ }^{3}$ Cardiosurgery Intensive Care Unit, S. Orsola-Malpighi Hospital, University of Bologna Medical School, Bologna, Italy.

Published: 11 September 2013

doi:10.1186/1749-8090-8-S1-0133

Cite this article as: Angeli et al:: Neonatal aortic coarctation: a spectrum of anatomic lesions repaired trough left thoracotomy in 22 years experience. Journal of Cardiothoracic Surgery 2013 8(Suppl 1):0133.

\footnotetext{
* Correspondence: emanuela.angeli3@unibo.it

'Pediatric and Adult Congenital Cardiac Surgery Unit, S. Orsola-Malpighi

Hospital, University of Bologna Medical School, Bologna, Italy

Full list of author information is available at the end of the article
}

(C) 2013 Angeli et al; licensee BioMed Central Ltd. This is an Open Access article distributed under the terms of the Creative Commons 